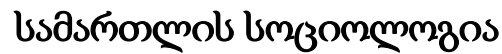

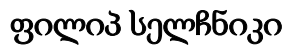

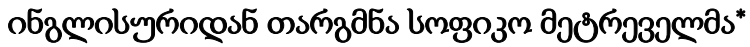

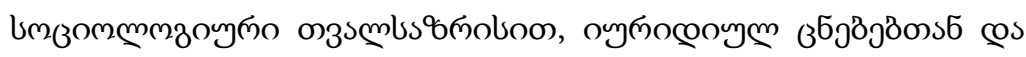

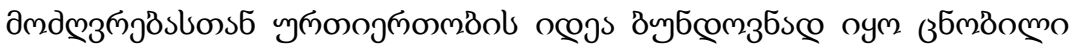

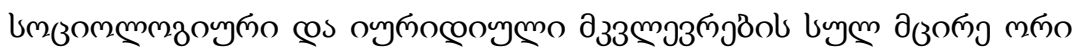

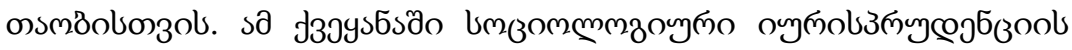

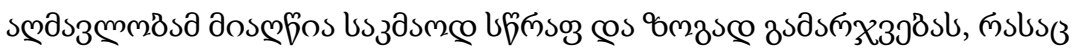

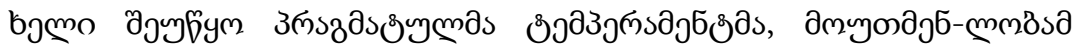

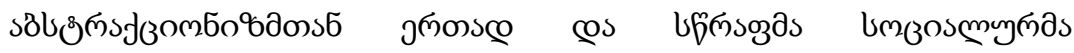

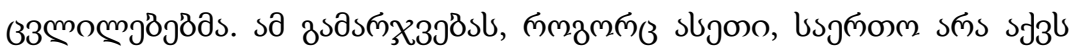

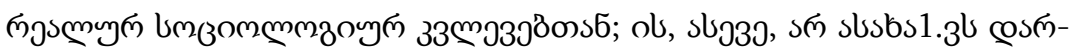

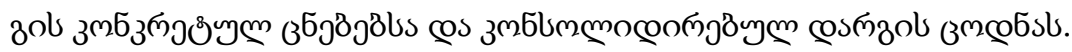

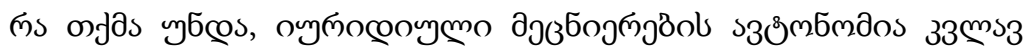

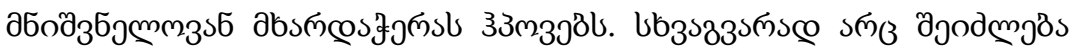

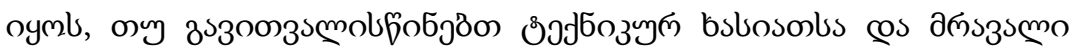

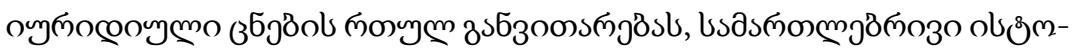

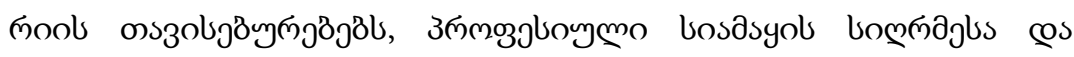

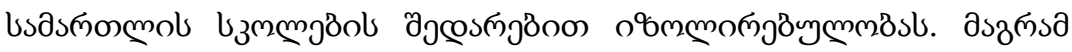

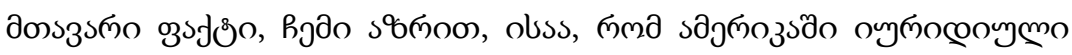

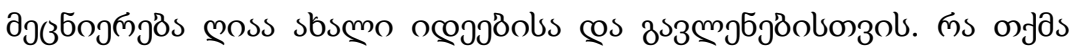

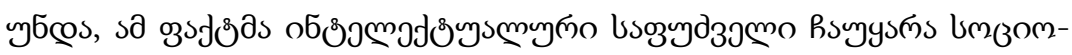

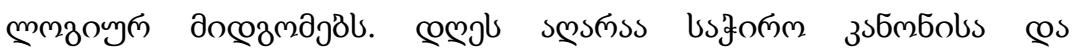

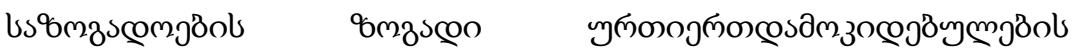

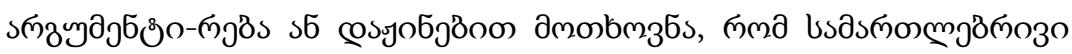

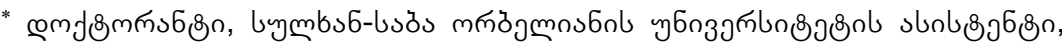

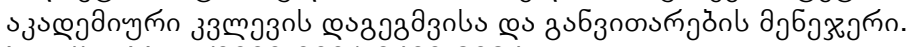

http://orcid.org/0000-0001-8480-2024
} 


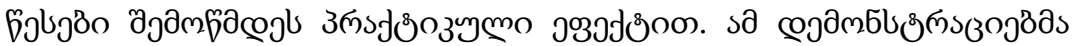

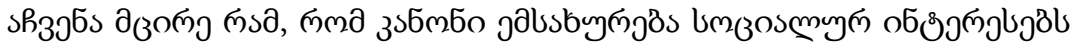

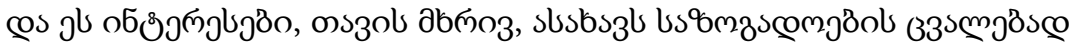

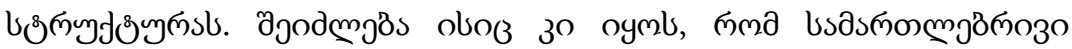

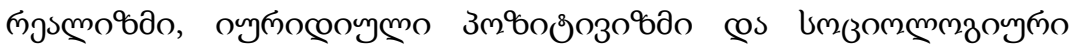

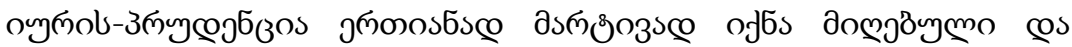

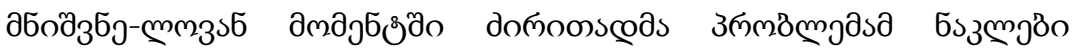

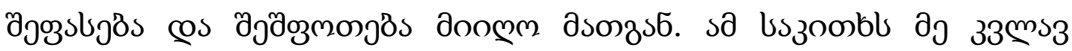

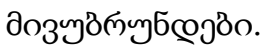

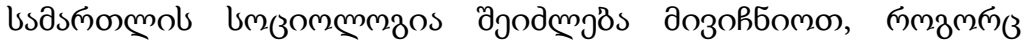

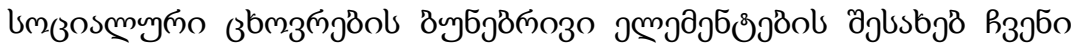

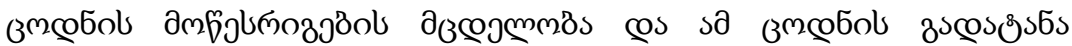

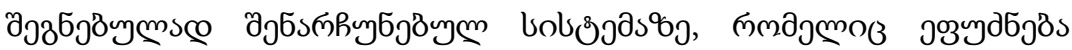

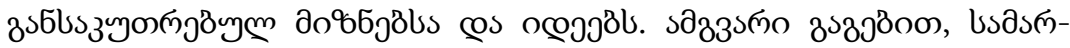

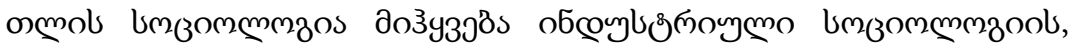

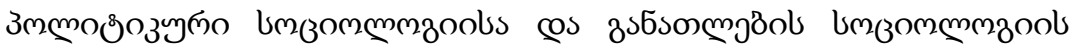

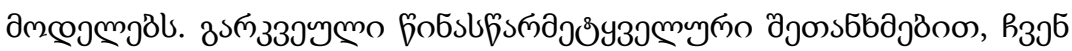

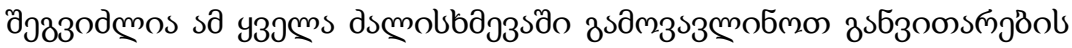

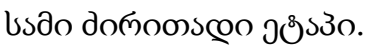

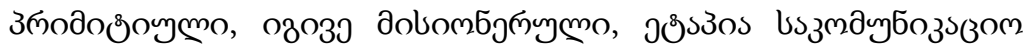

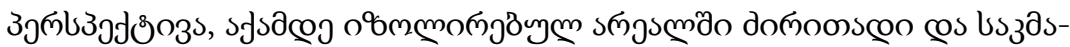

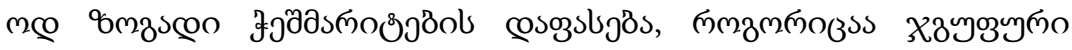

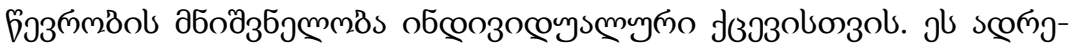

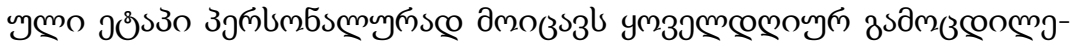

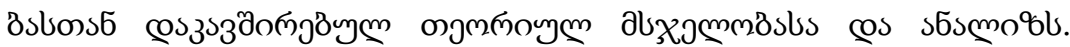

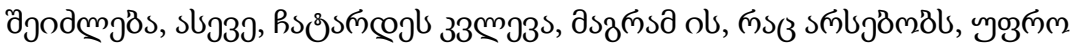

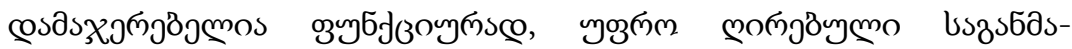

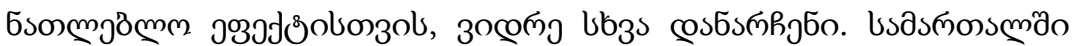

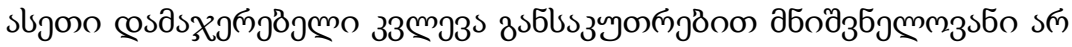

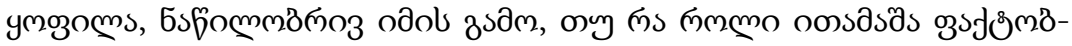

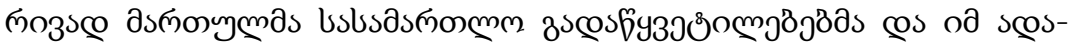




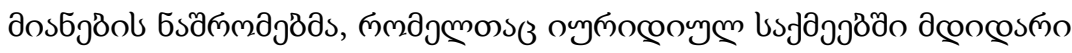

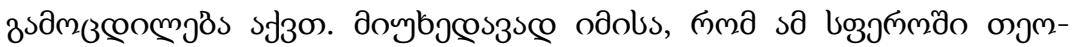

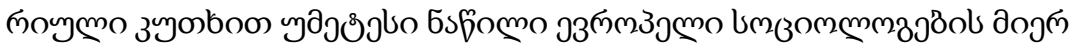

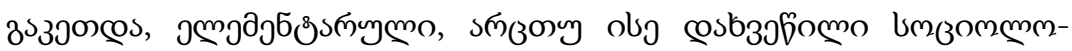

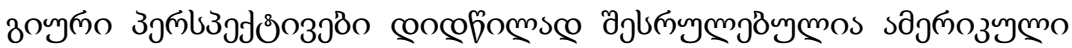

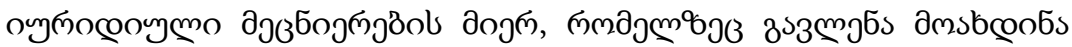

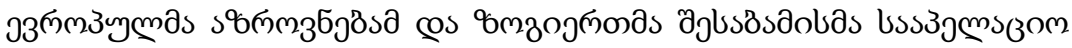

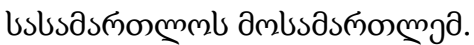

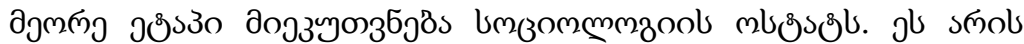

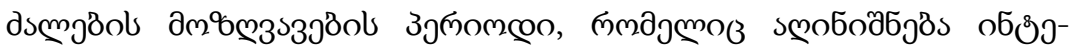

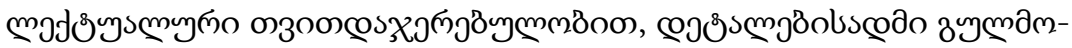

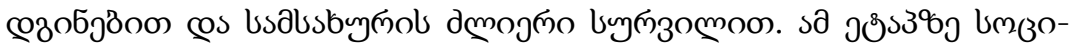

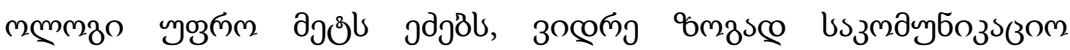

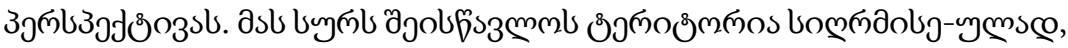

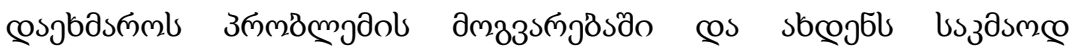

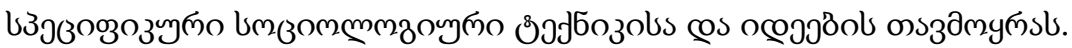

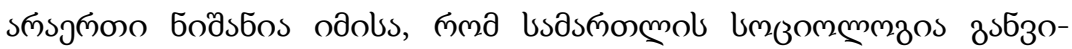

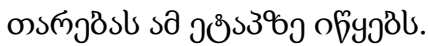

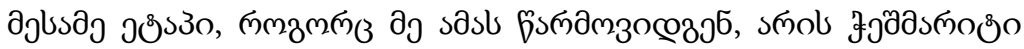

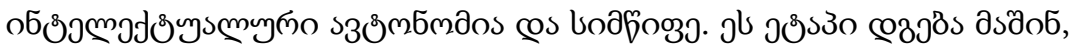

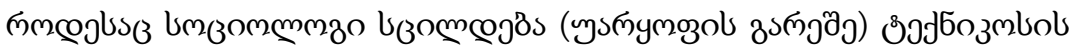

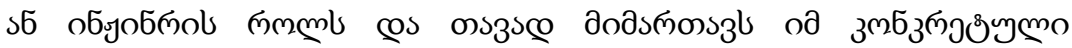

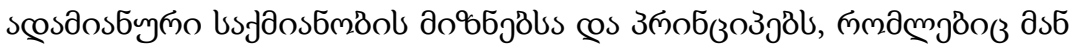

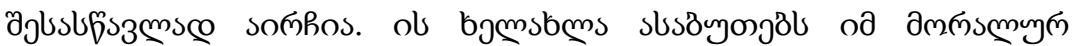

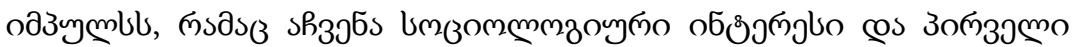

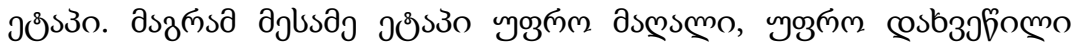

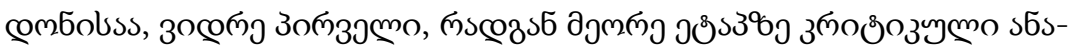

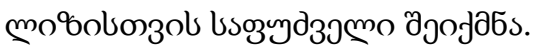

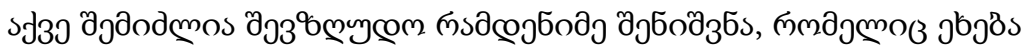

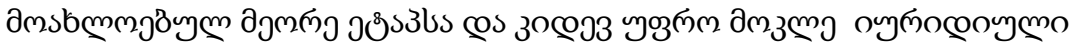

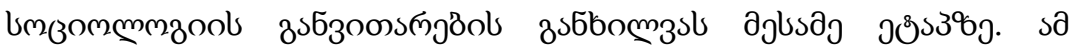




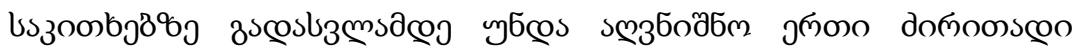

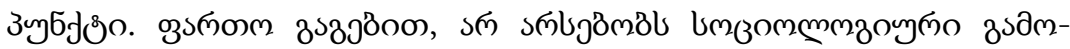

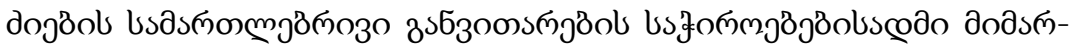

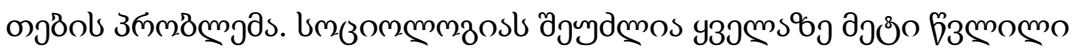

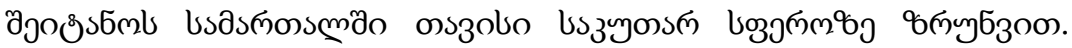

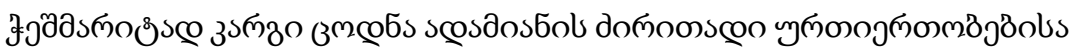

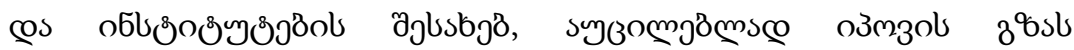

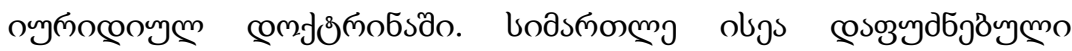

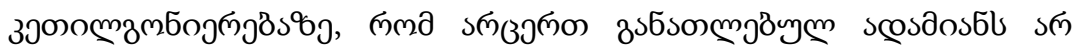

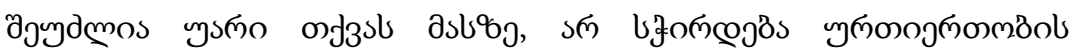

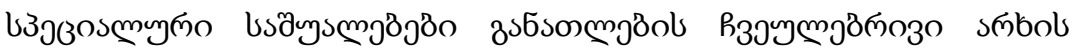

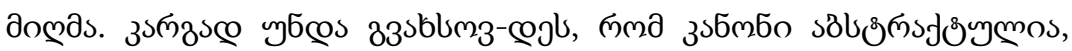

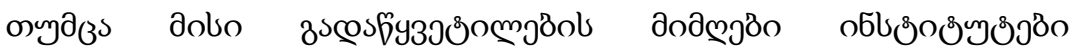

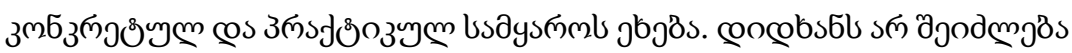

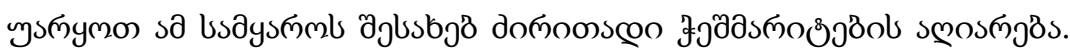

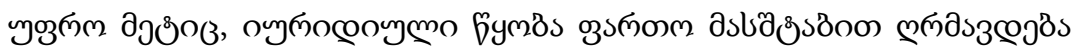

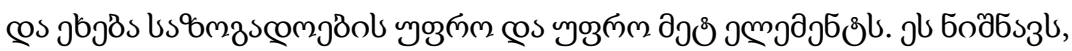

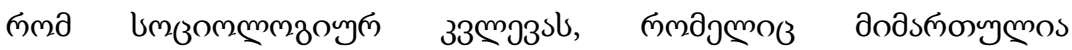

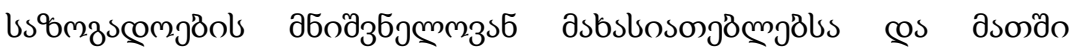

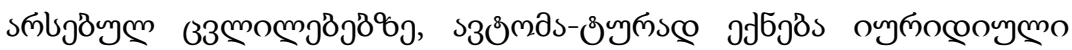

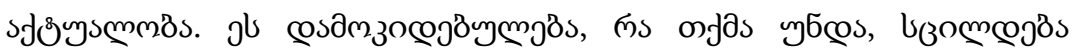

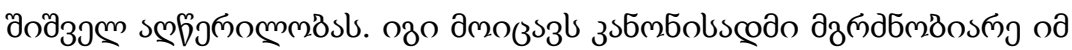

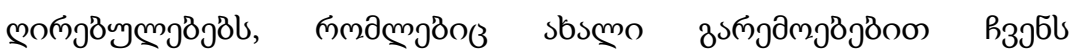

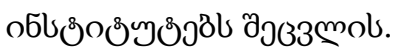

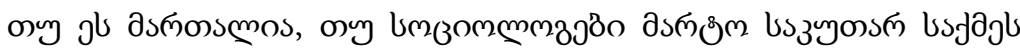

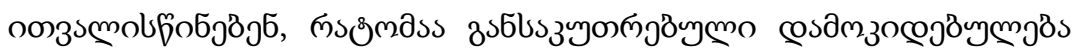

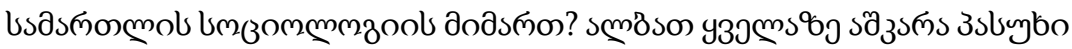

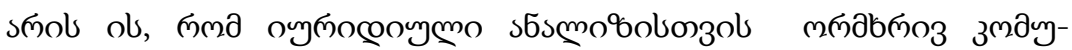

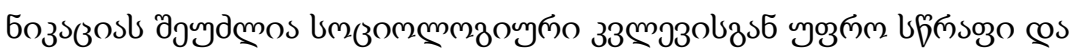

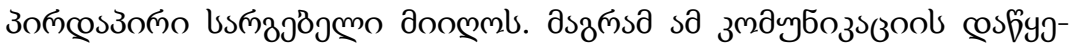

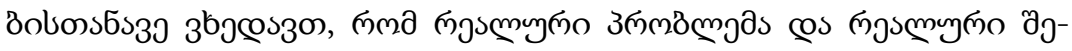




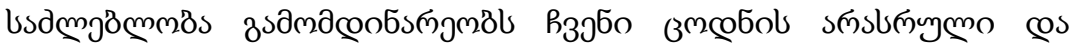

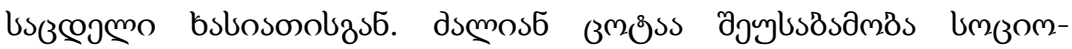

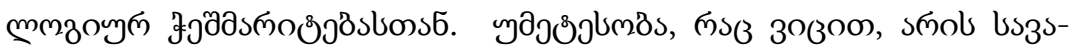

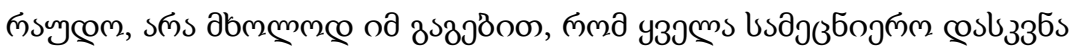

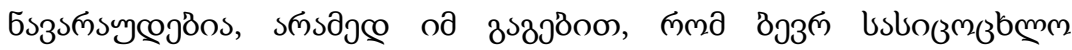

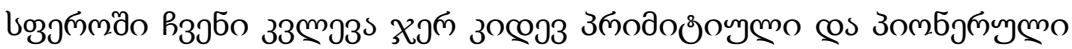

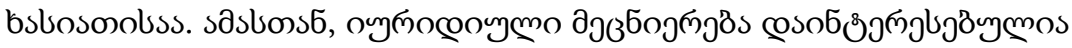

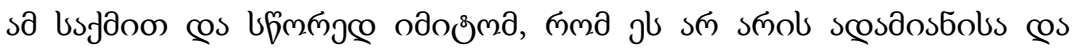

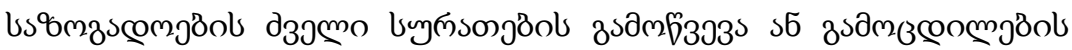

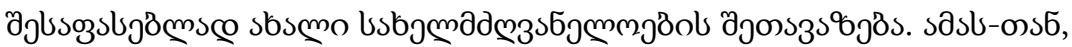

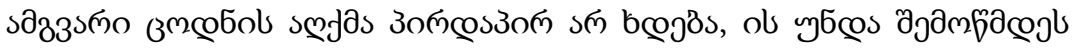

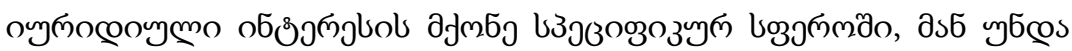

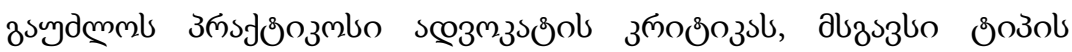

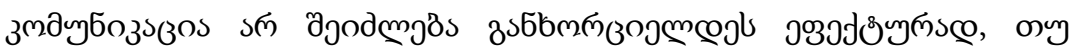

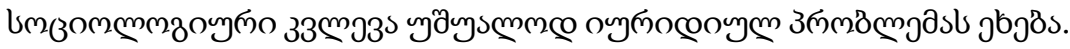

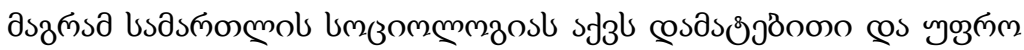

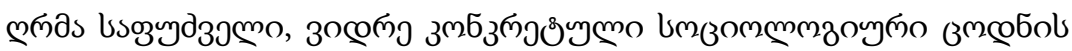

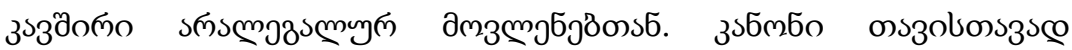

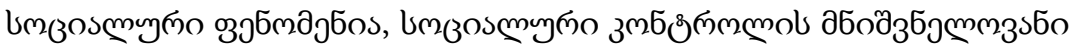

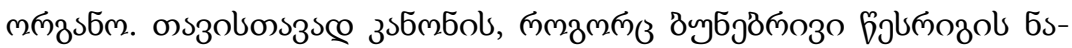

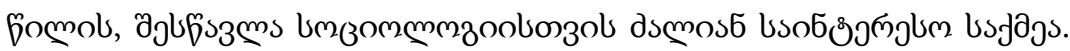

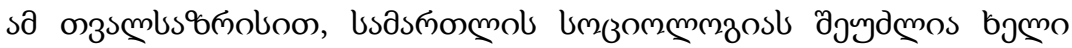

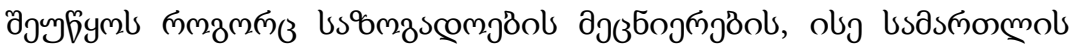

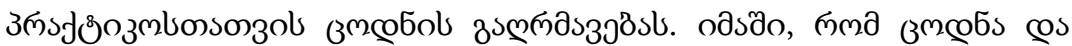

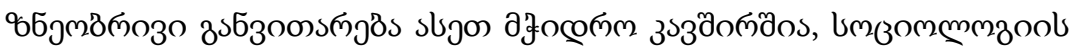

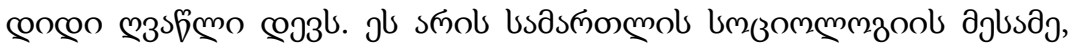

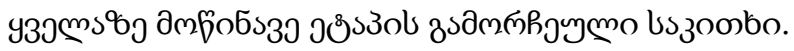

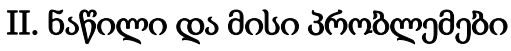




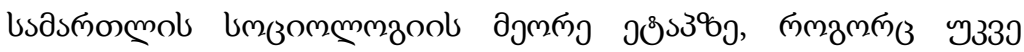

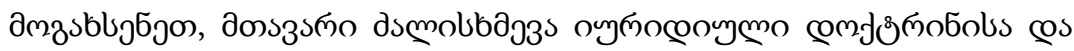

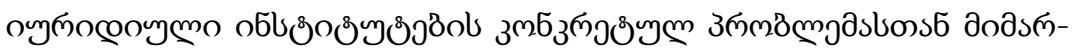

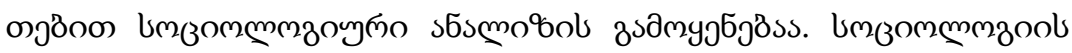

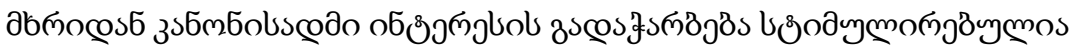

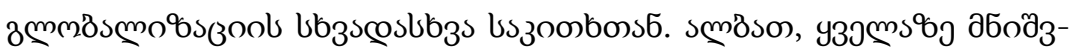

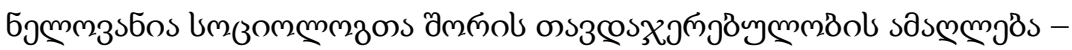

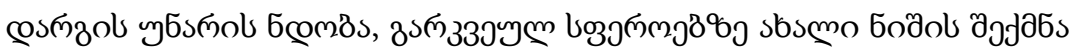

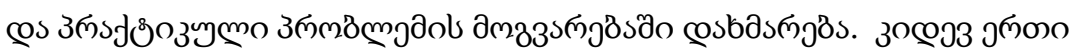

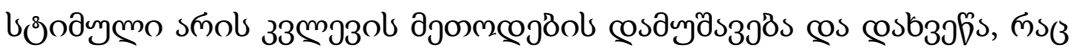

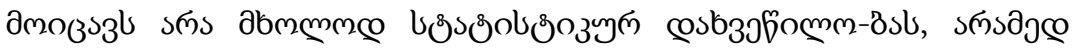

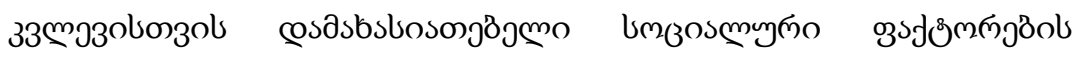

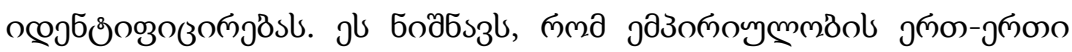

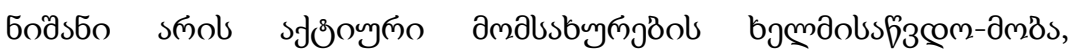

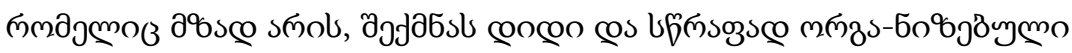

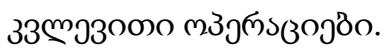

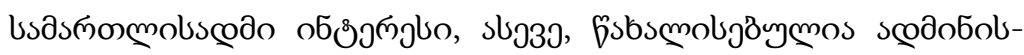

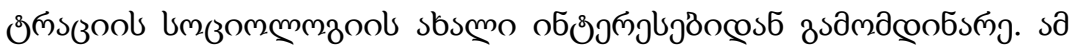

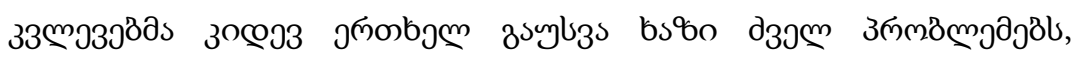

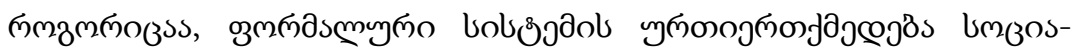

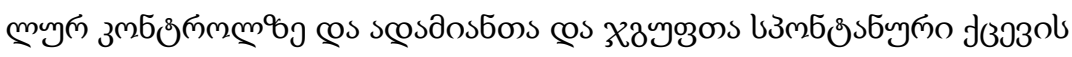

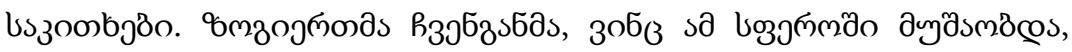

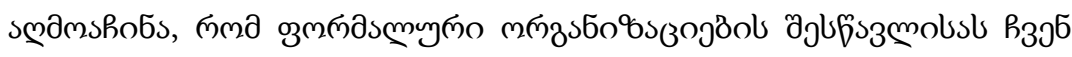

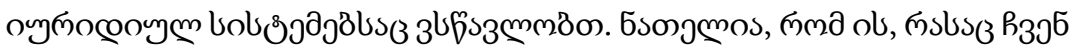

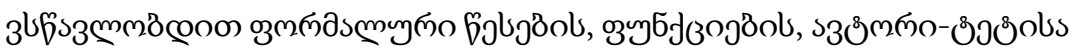

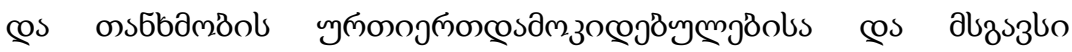

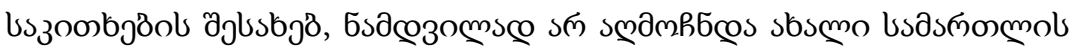

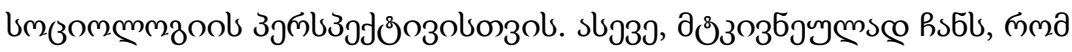

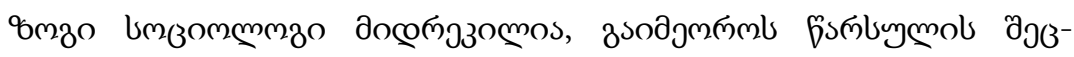

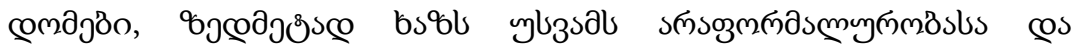




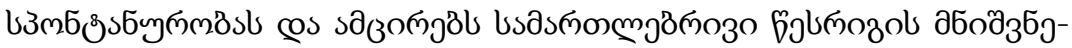

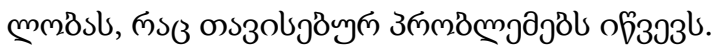

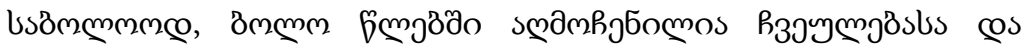

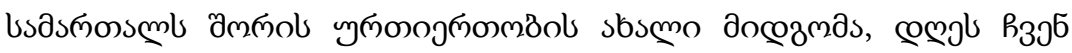

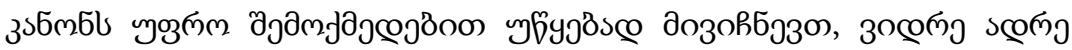

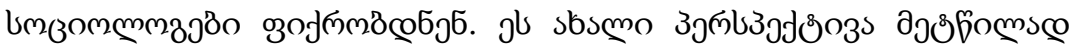

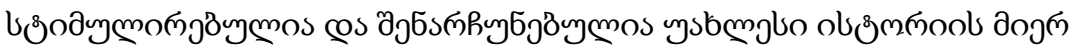

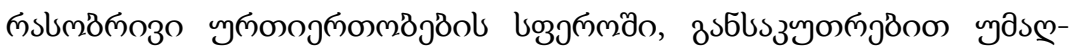

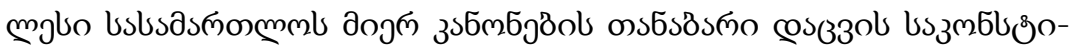

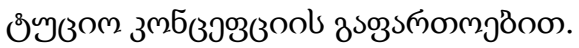

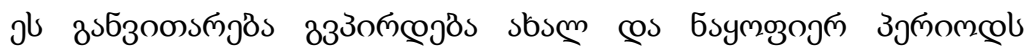

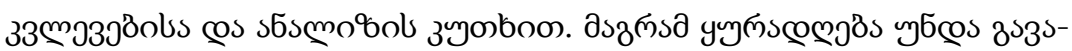

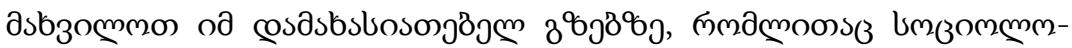

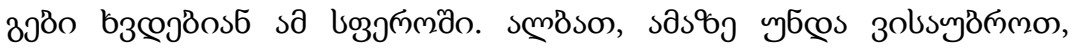

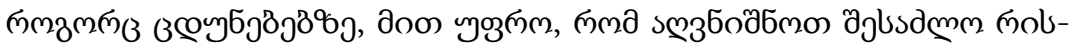

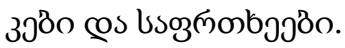

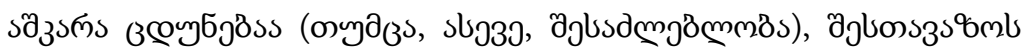

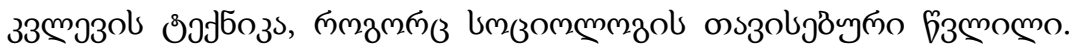

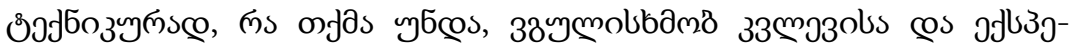

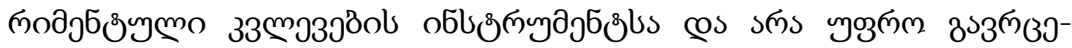
мэвулмо ов

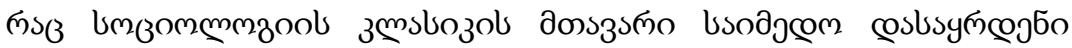

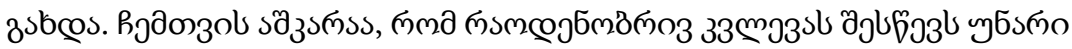

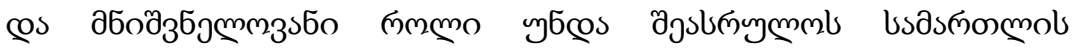
uмзомемпзоздо.

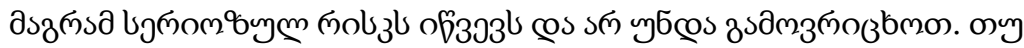

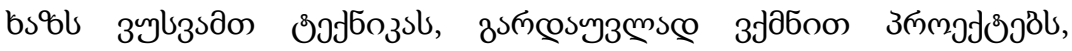

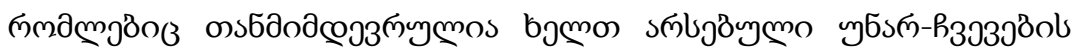

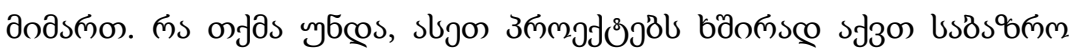

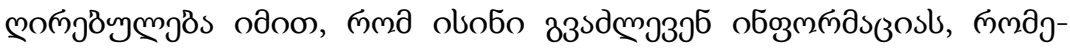

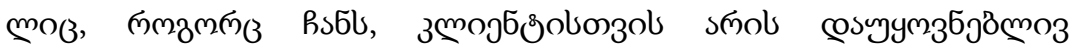




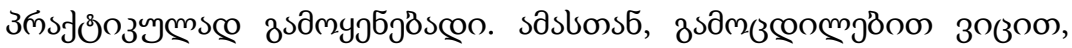

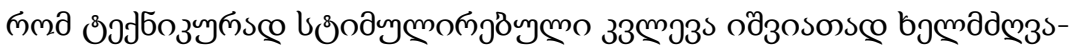

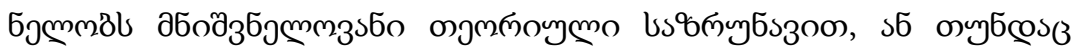

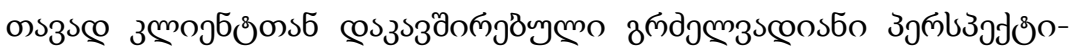

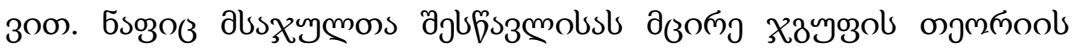

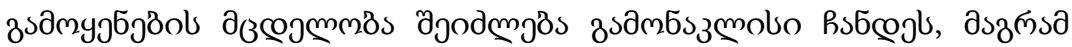

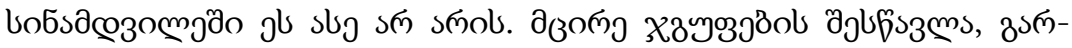

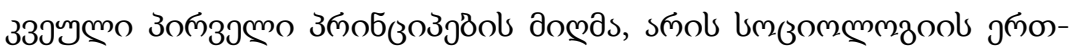

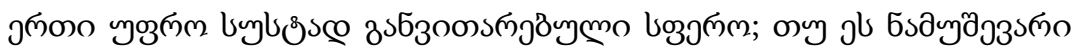

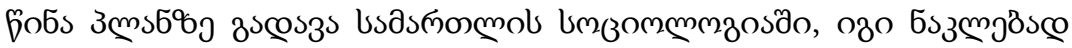

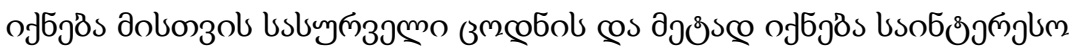

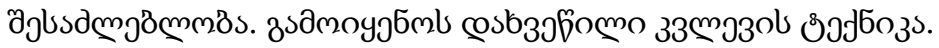

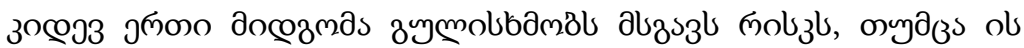

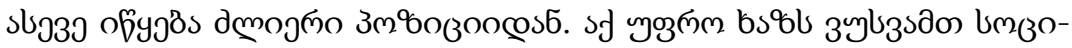

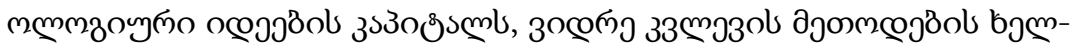

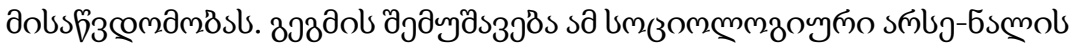

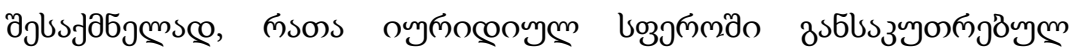

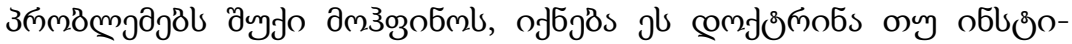

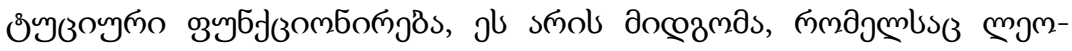

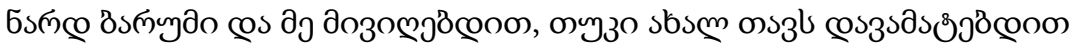

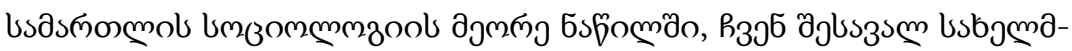

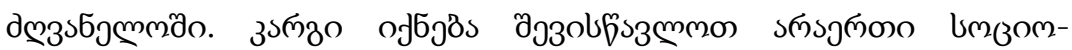

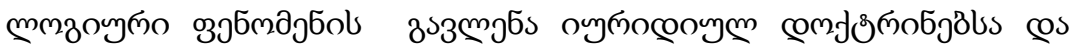

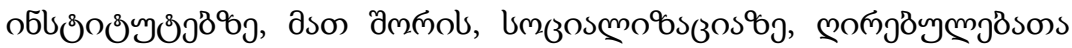

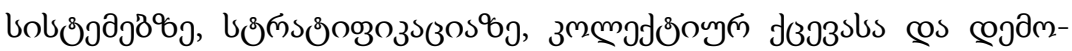

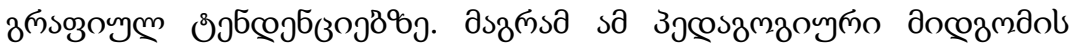

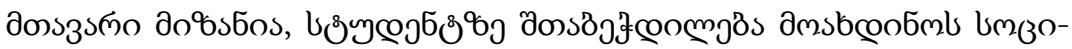
меммзоупо змб

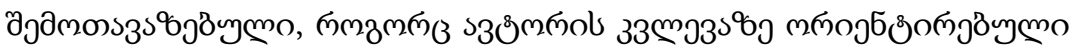

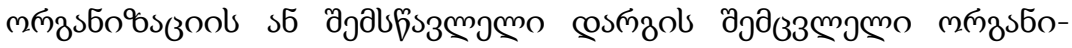

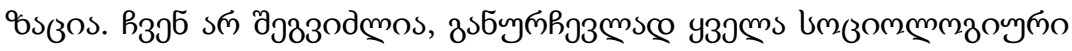




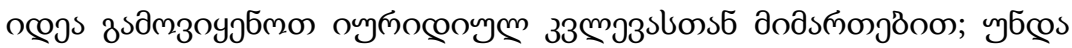

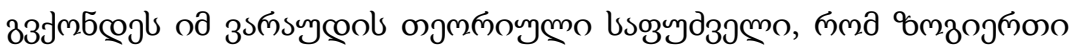

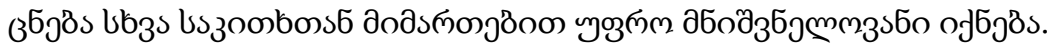

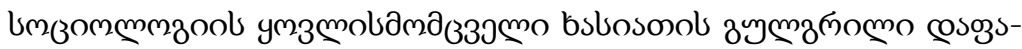

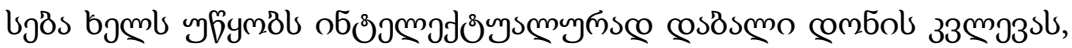

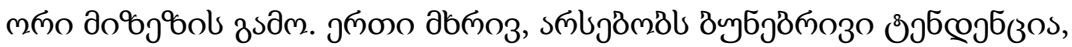

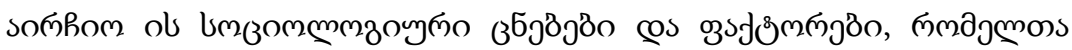

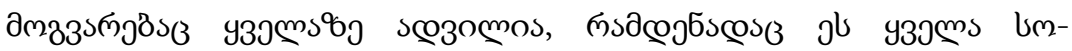

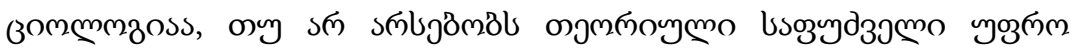

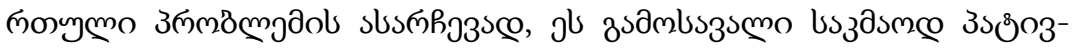

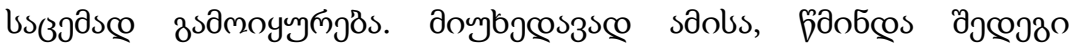

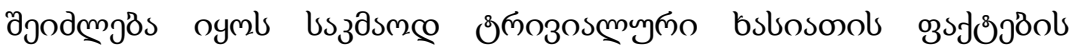

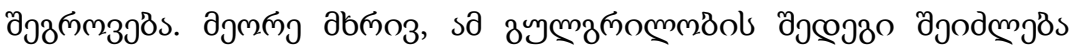

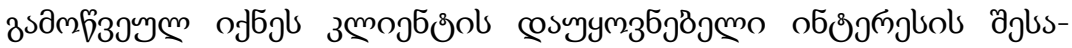

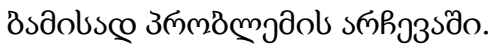

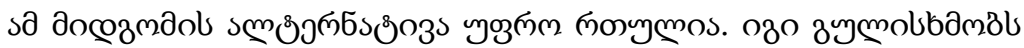

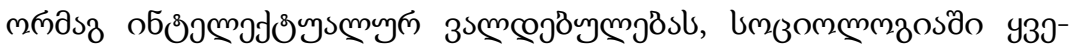

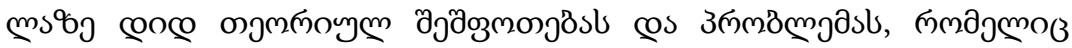

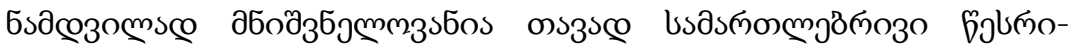

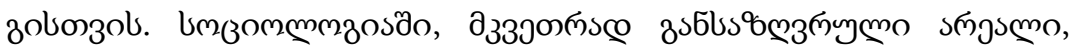

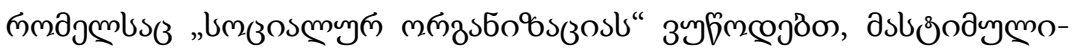

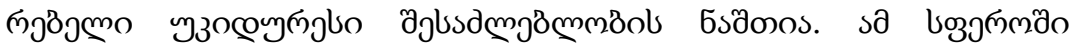

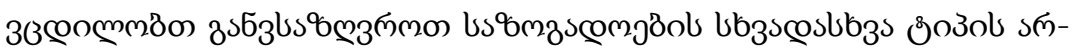

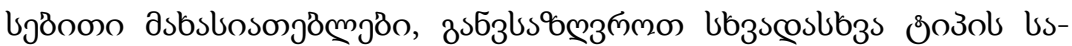

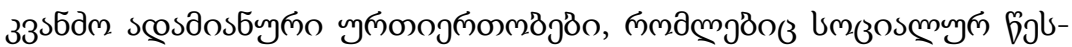

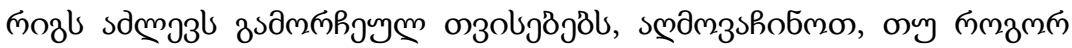

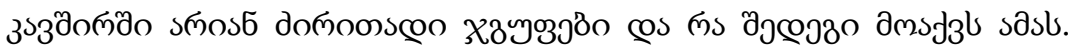

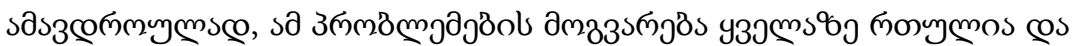

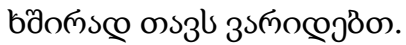

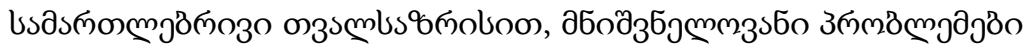

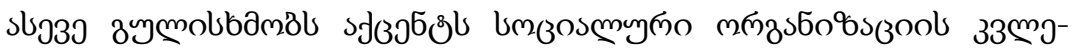




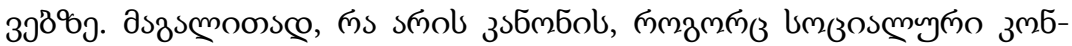

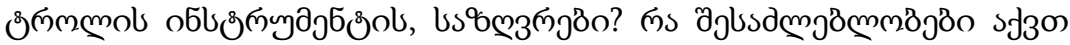

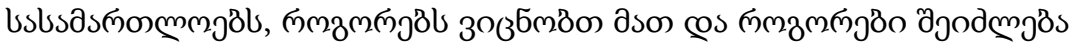

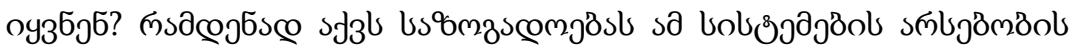

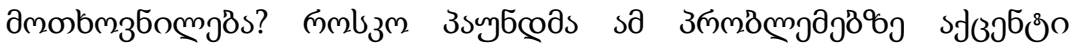

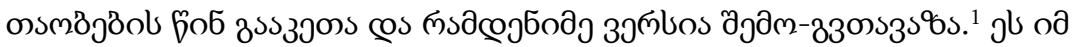

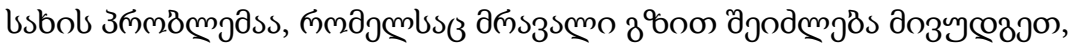

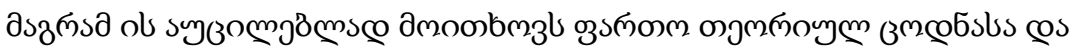

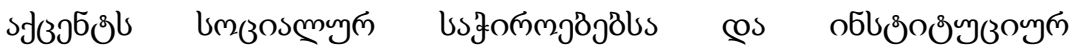

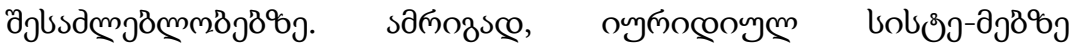

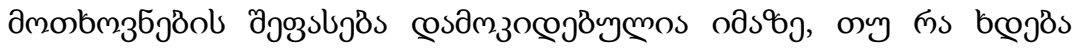

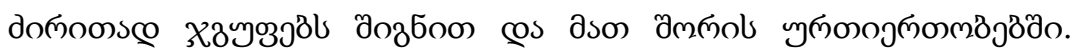

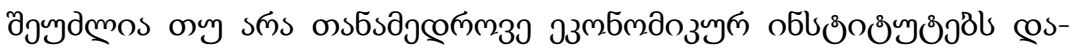

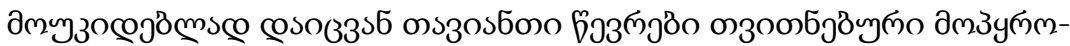

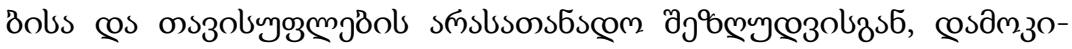

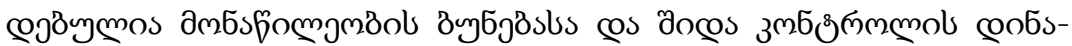

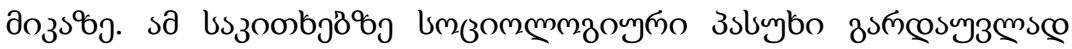

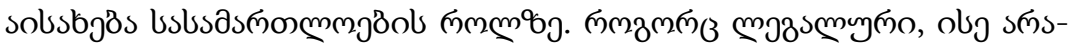

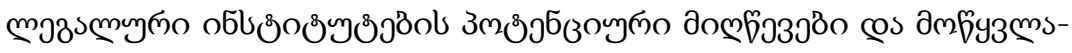

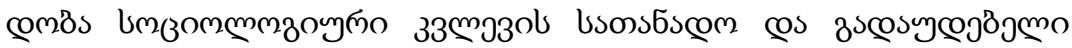
uszoombos.

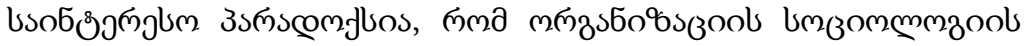

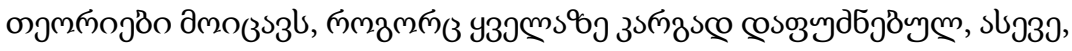

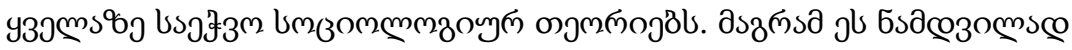

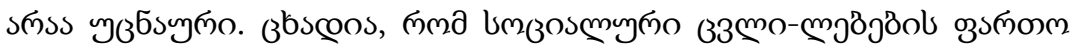

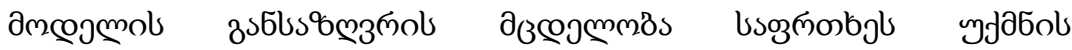

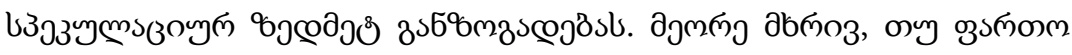

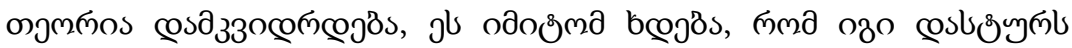

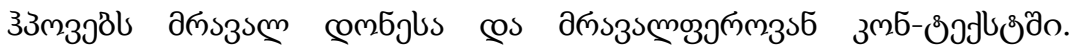

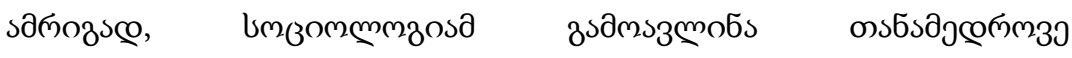

1 Pound, The Limits of Effective Legal Action, 27 INT'L J. ETHICS 150 (1917). 


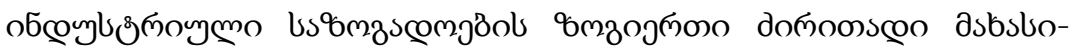

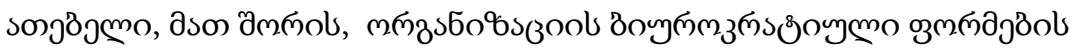

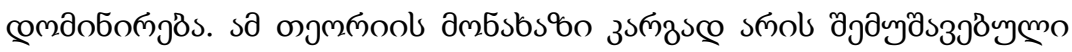

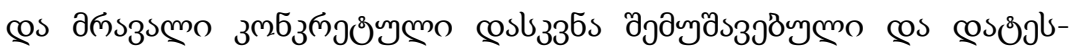

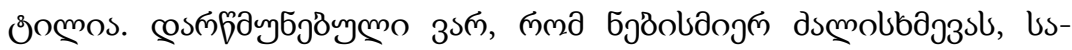

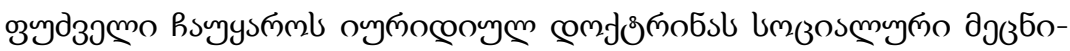

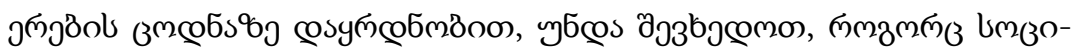

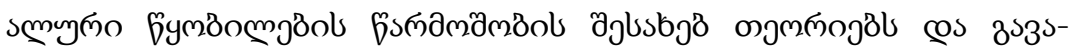

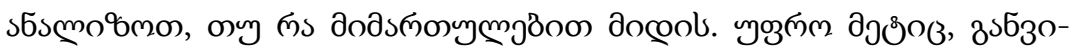

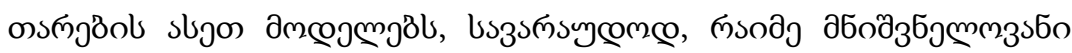

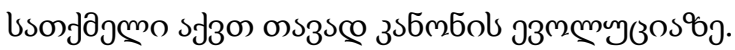

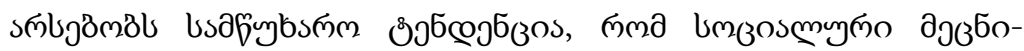

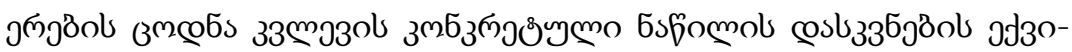

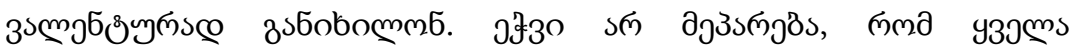

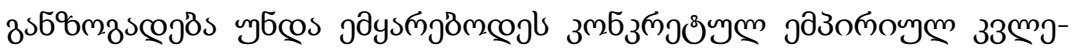

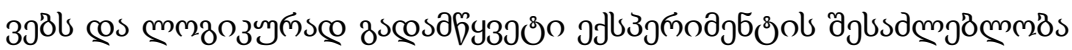

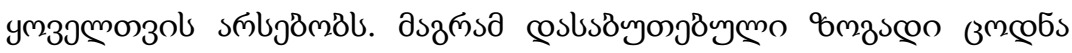

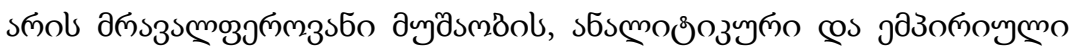

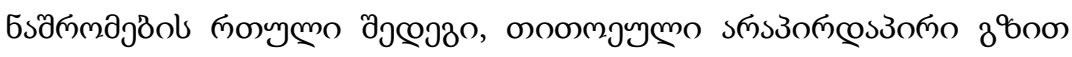

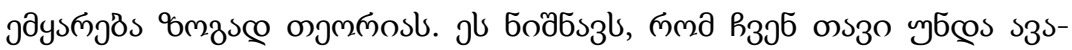

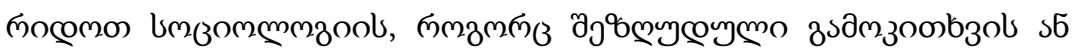

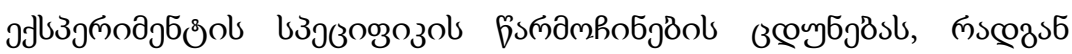

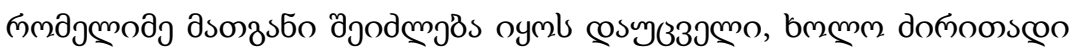

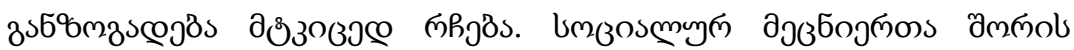

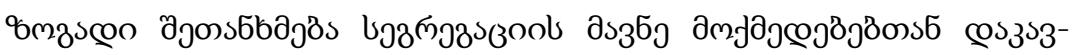

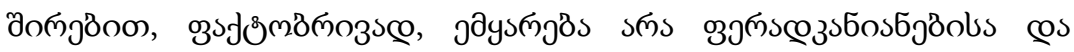

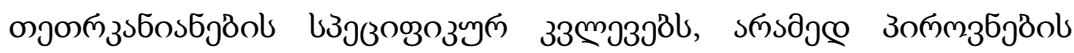

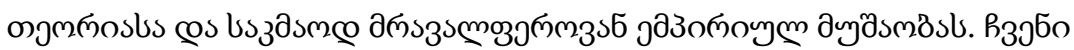

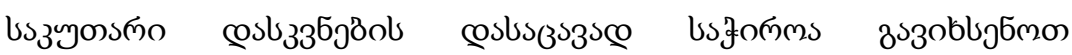

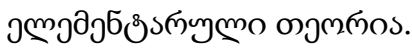




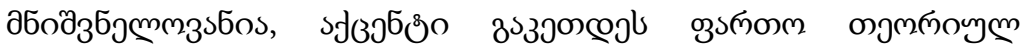

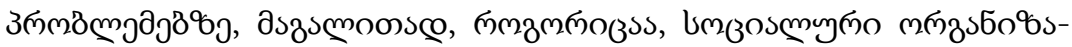

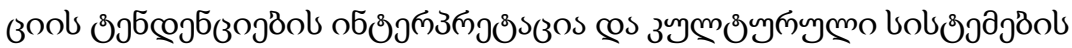

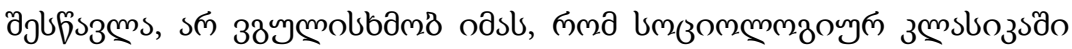

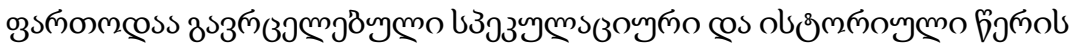

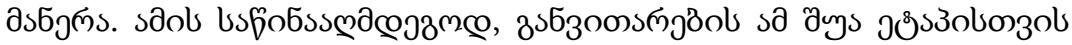

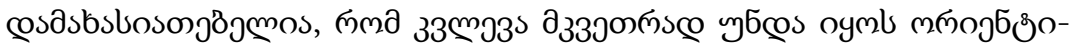

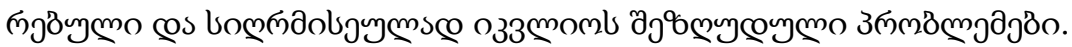

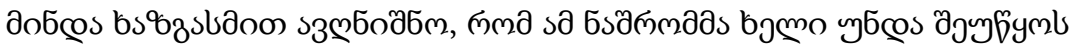

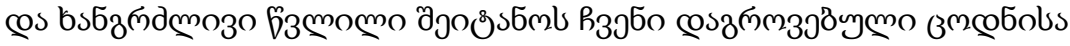

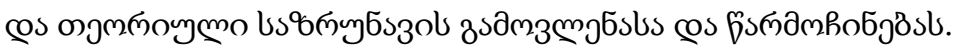

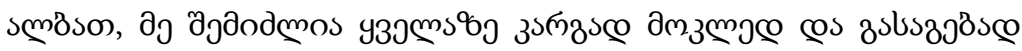

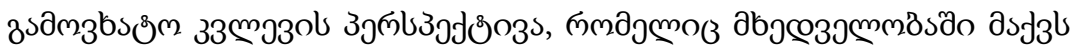

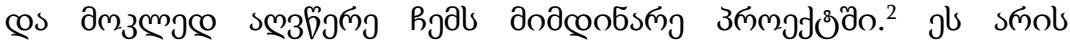

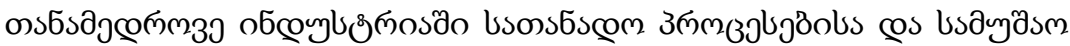

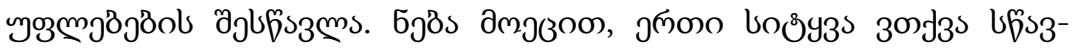

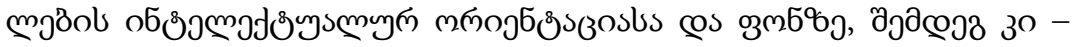

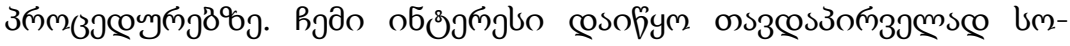

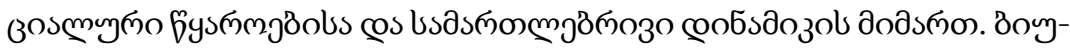

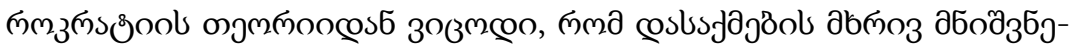

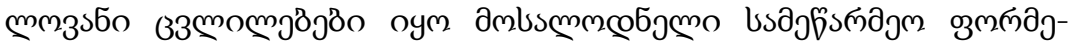

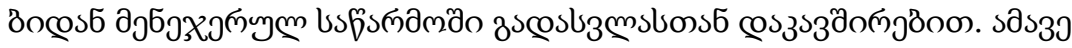

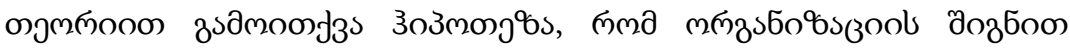

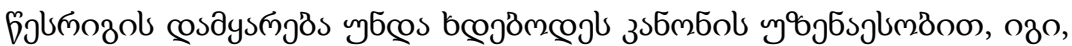

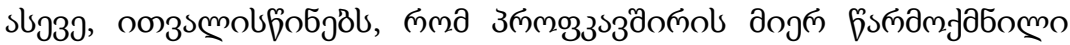

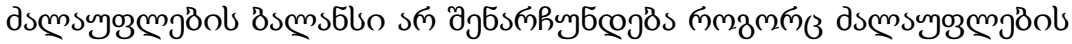

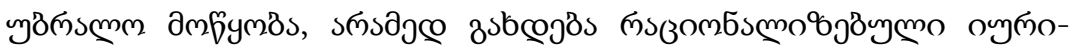

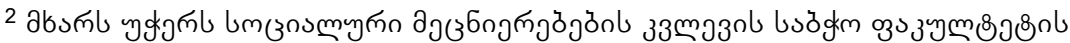

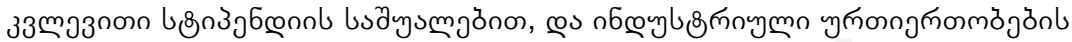

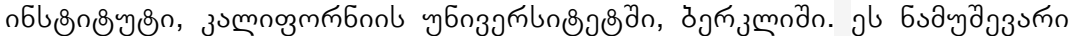

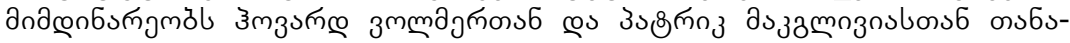

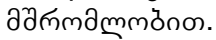




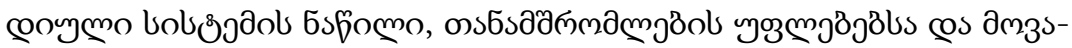

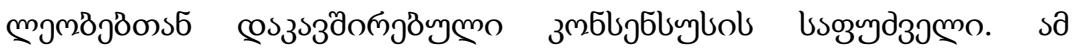

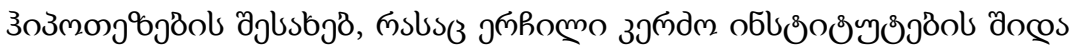

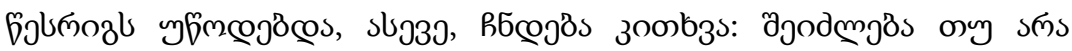

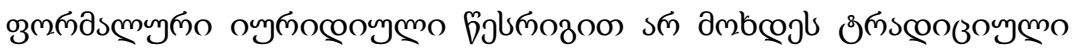

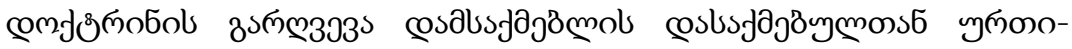

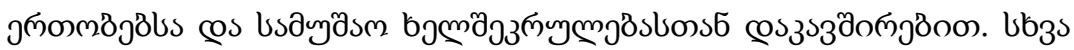

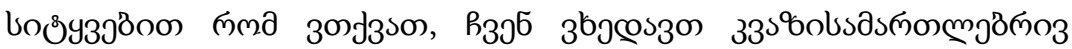

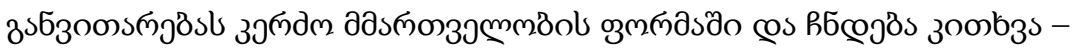

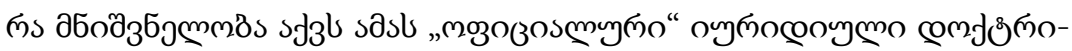

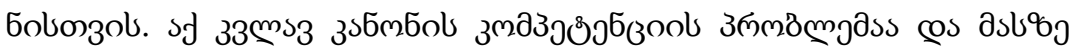

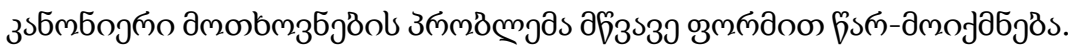

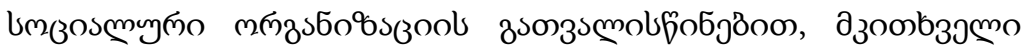

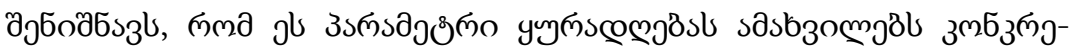

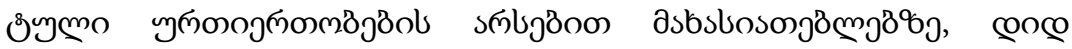

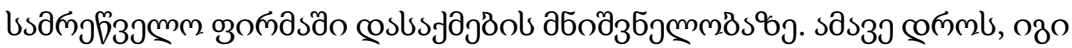

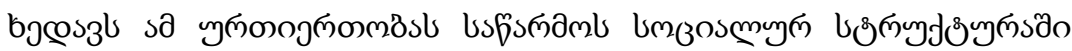

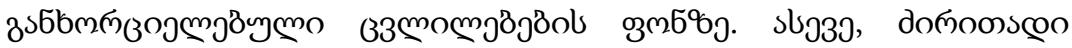

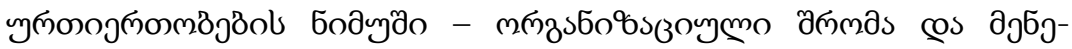

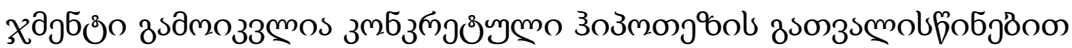

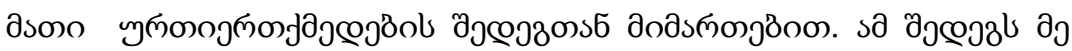

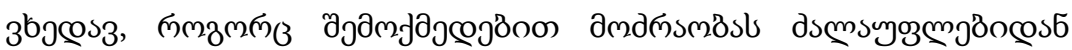

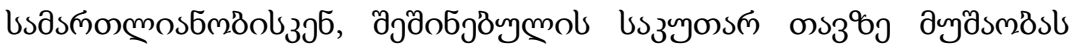

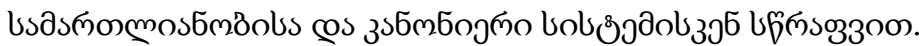

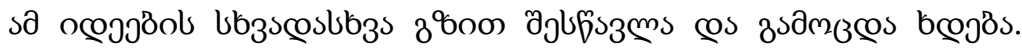

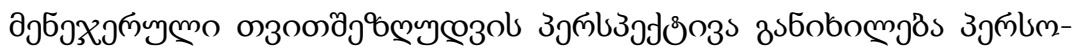

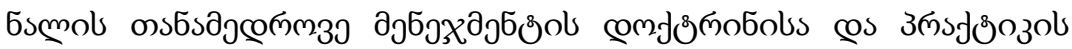

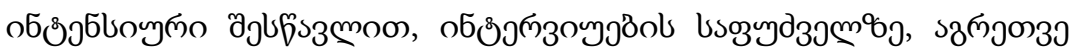

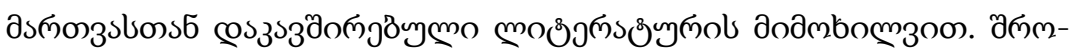

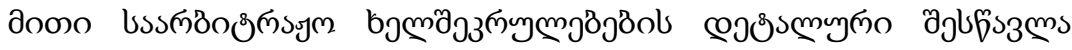

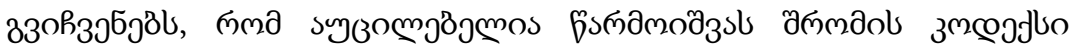




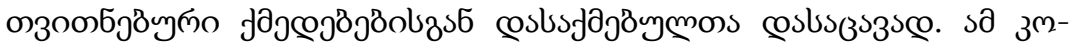

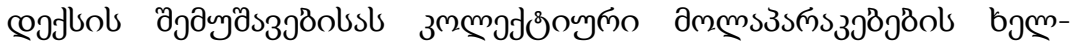

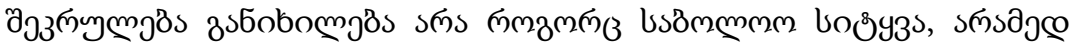

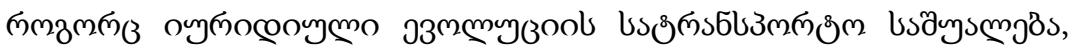

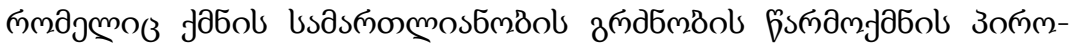

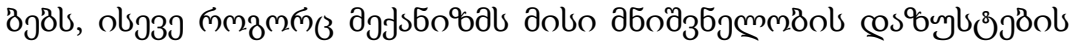

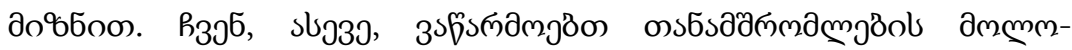

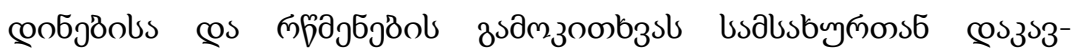

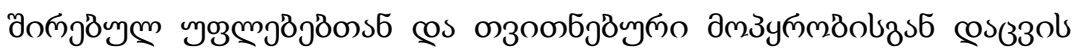

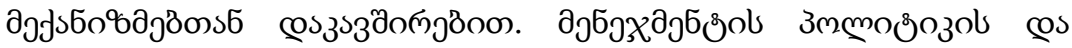

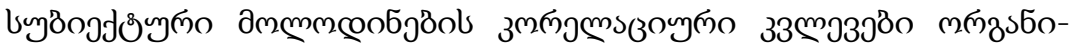

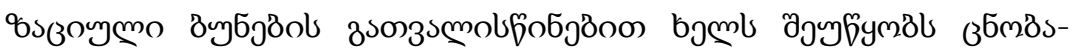

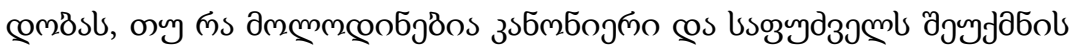

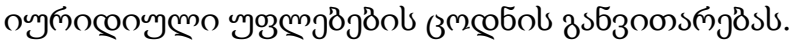

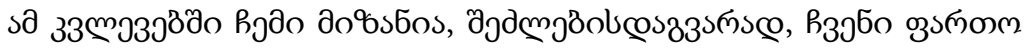

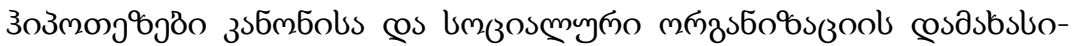

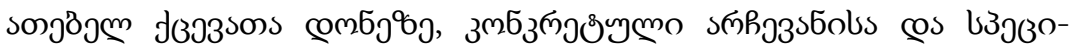

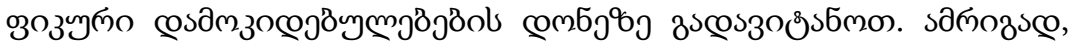

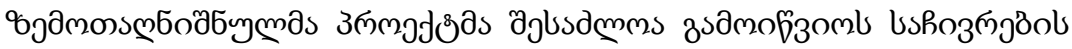

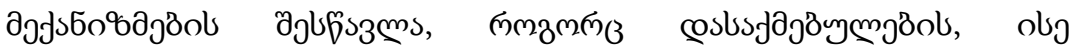

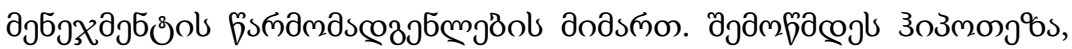

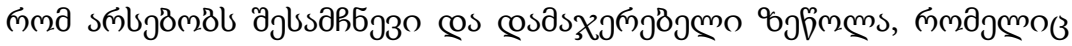

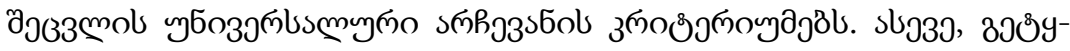

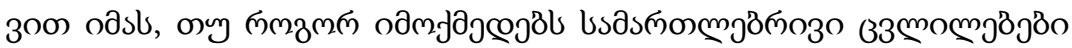

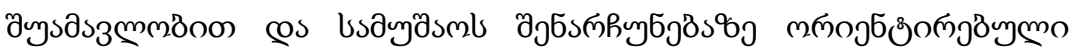

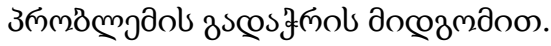

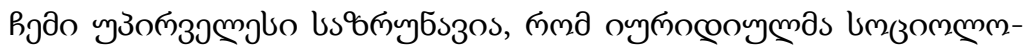

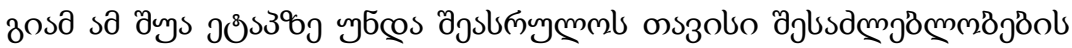

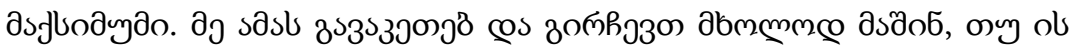

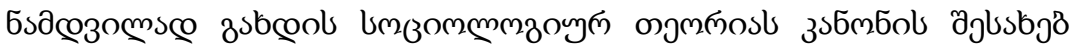

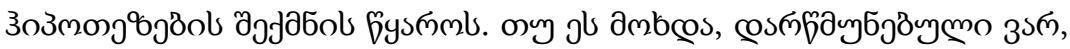




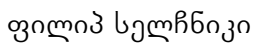

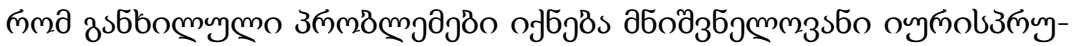
cj5 (3ool कзs

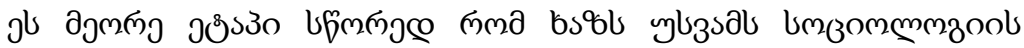

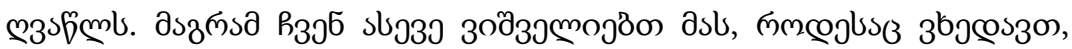

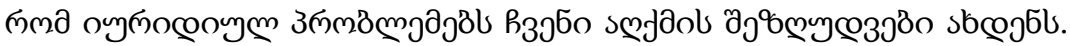

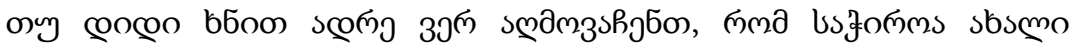

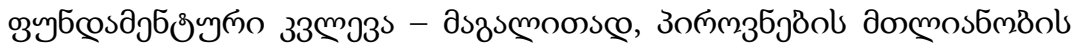

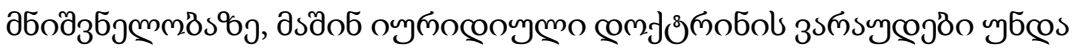

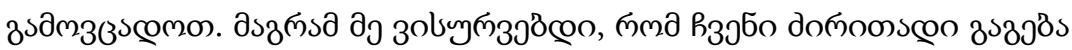

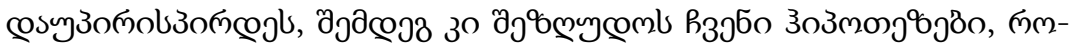

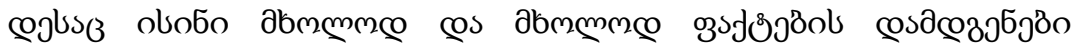
zsbejöosб.

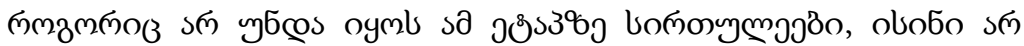

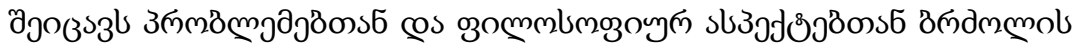

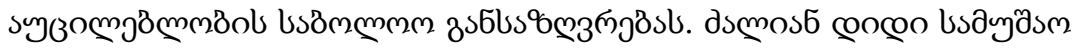

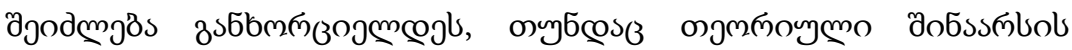

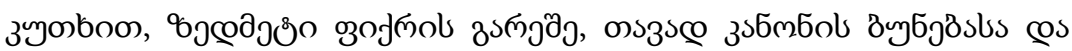

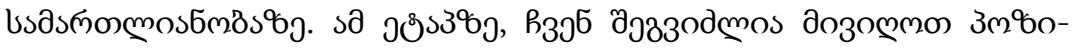

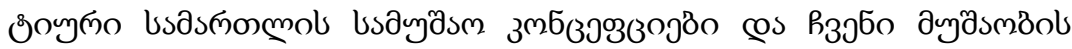

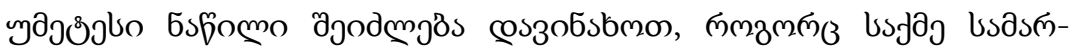

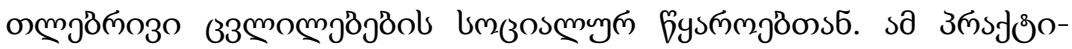

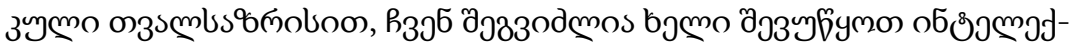

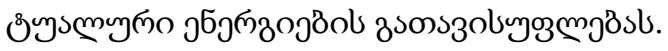

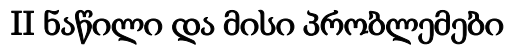

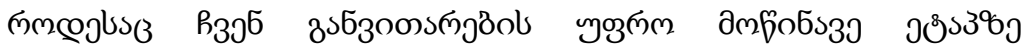

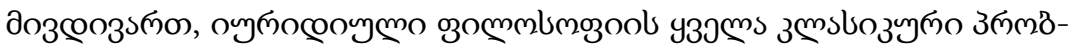
mjas з3ms

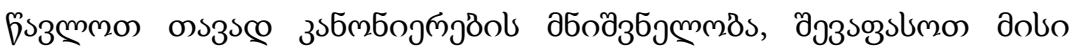

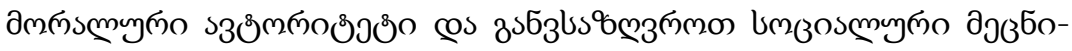


jங

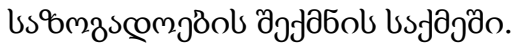

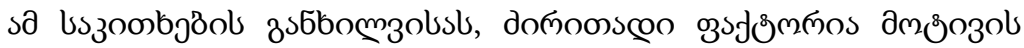

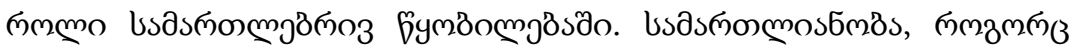

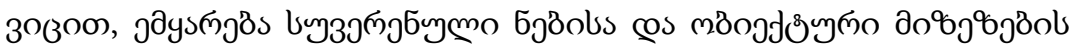

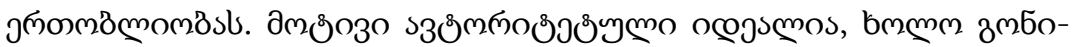

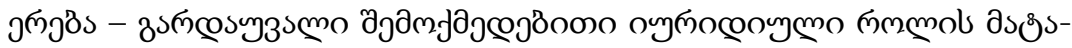

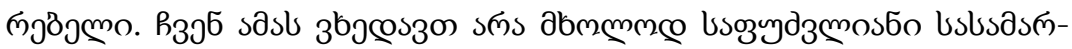

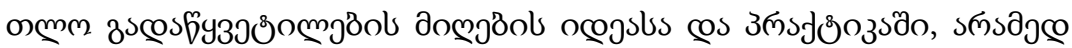

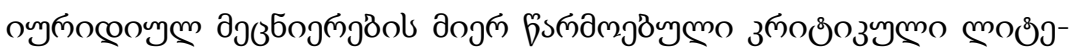

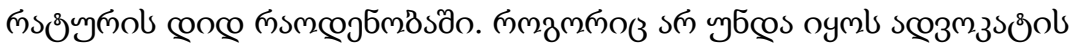

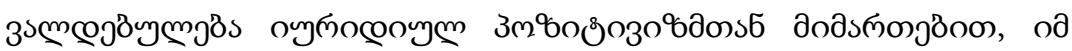

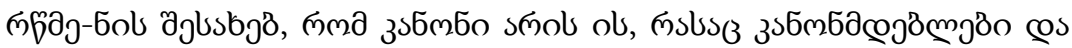

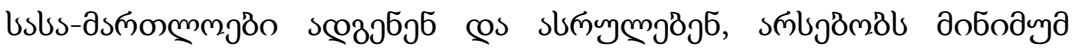

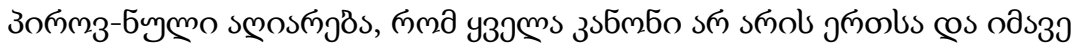

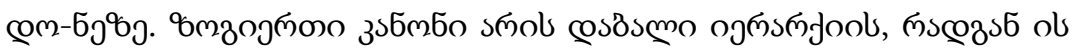

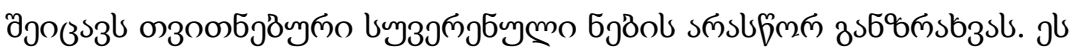

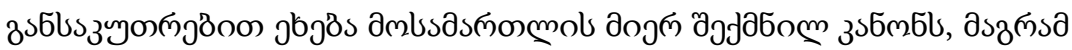

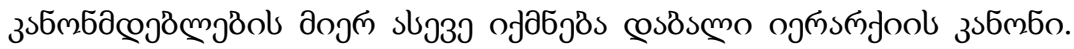

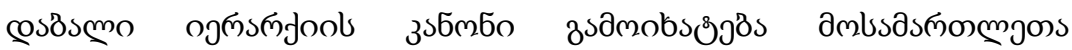

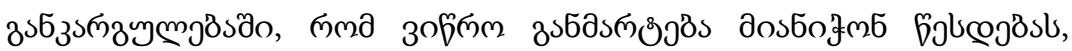

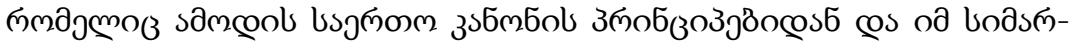

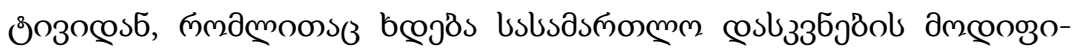

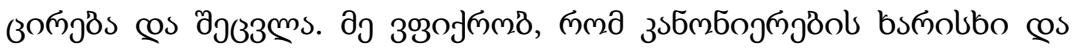

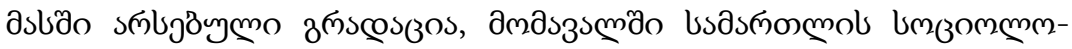

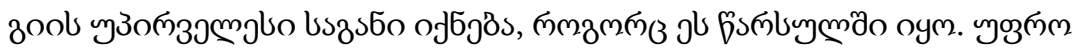

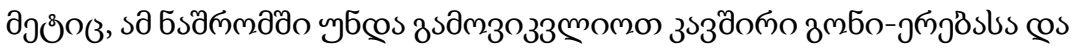

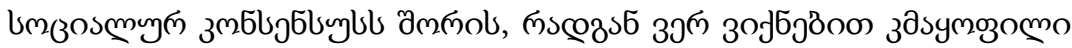

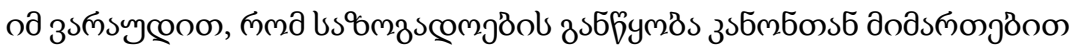

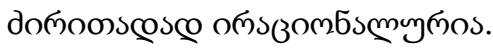




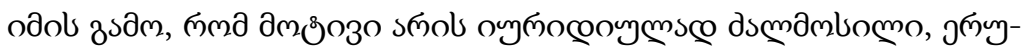

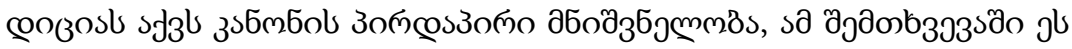

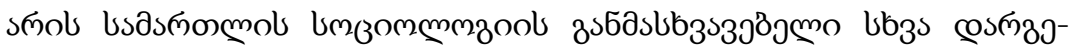

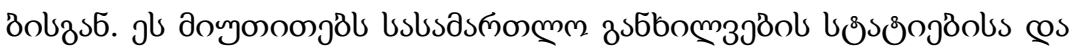

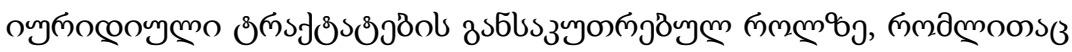

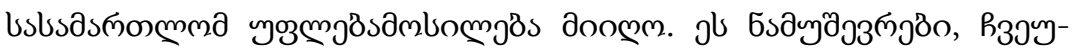

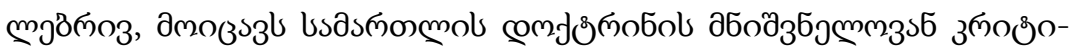

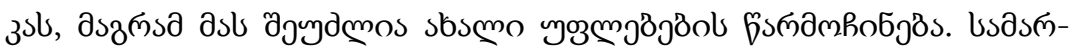
омо з з

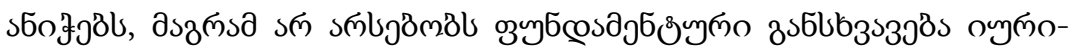

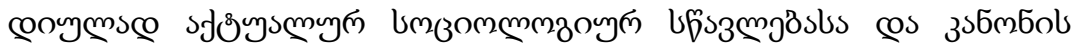

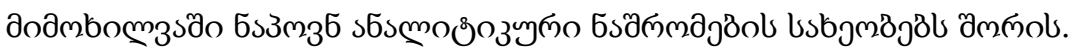

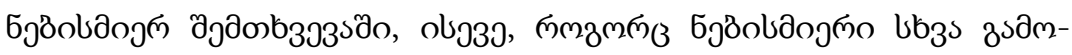

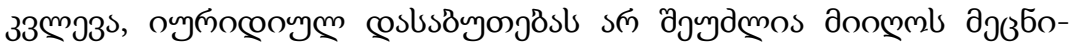

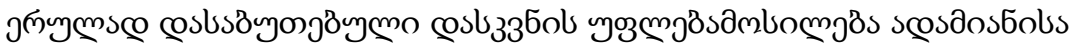

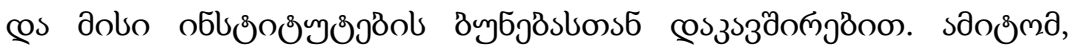

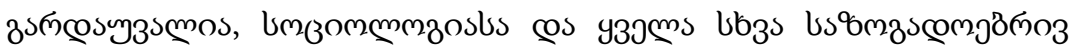

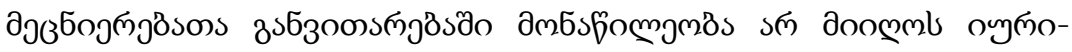

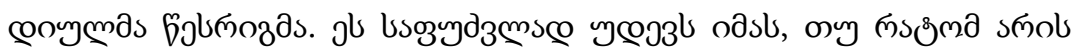

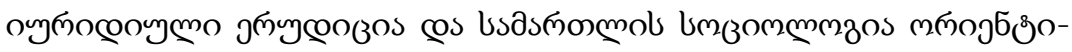

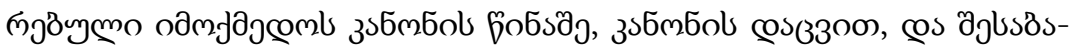

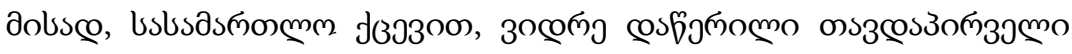

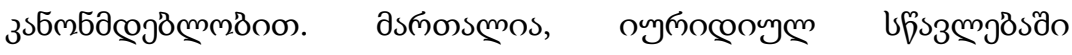

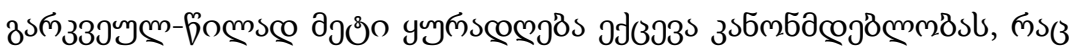

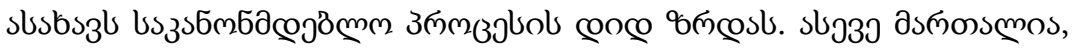

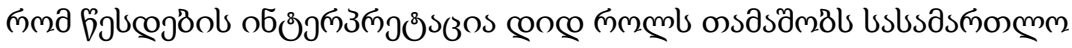

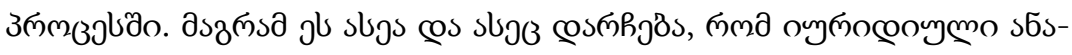

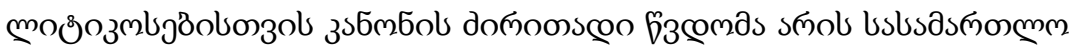

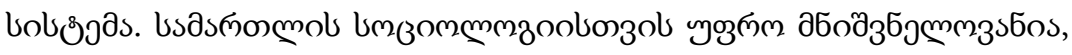

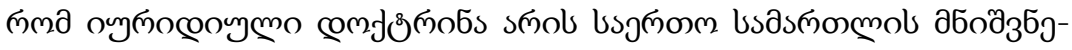




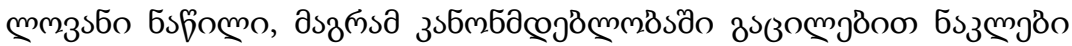
дбодаб

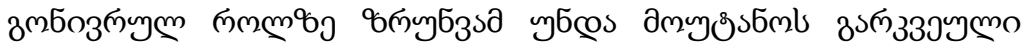

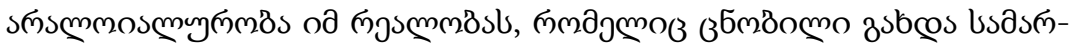

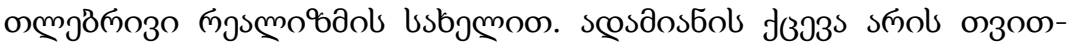

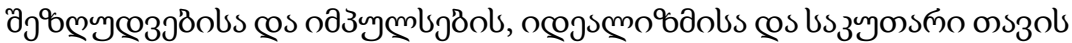

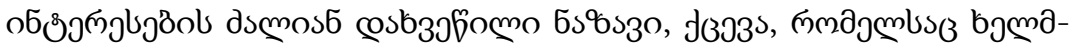

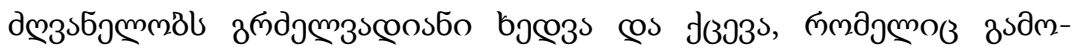

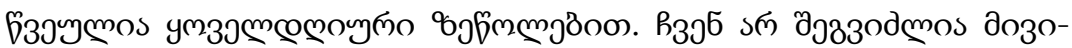

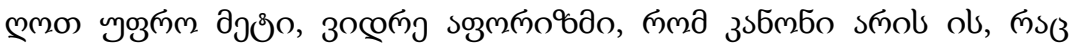

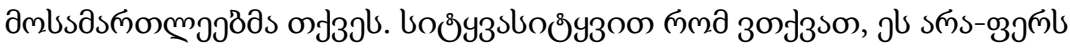

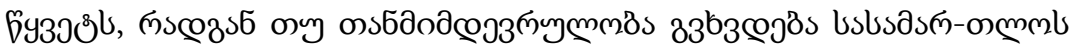

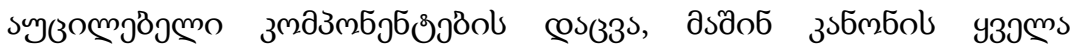

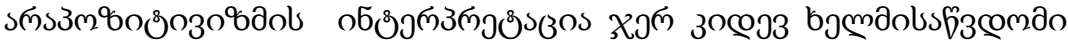

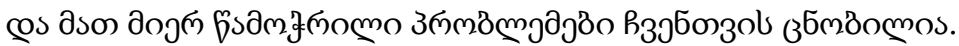

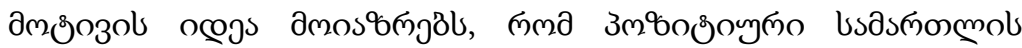

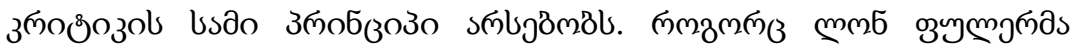

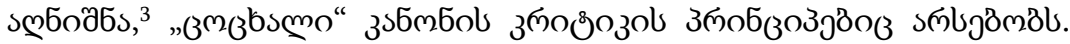

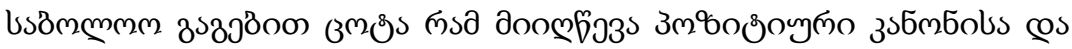

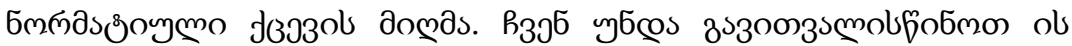

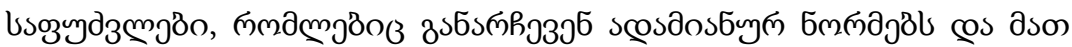

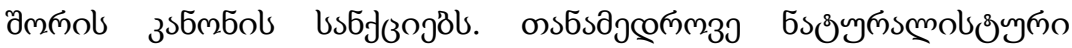

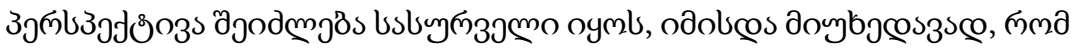

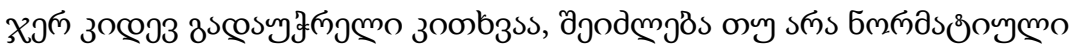

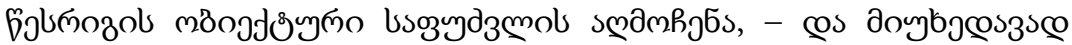

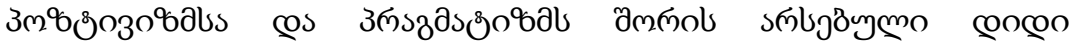

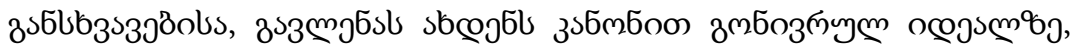

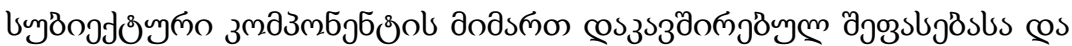

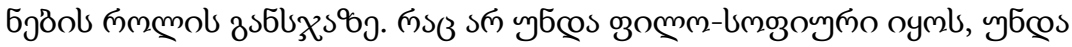

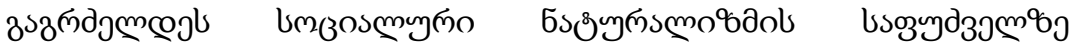

${ }^{3}$ Fuller, American Legal Realism, 82 U.PAL.REv. 40 (1934). 


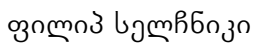

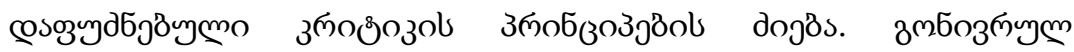

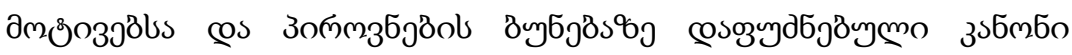

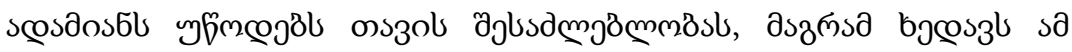

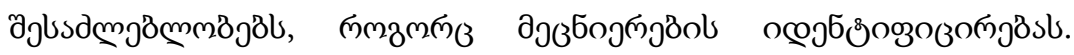

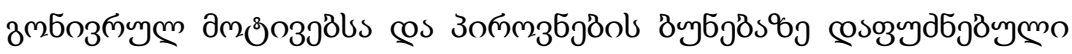

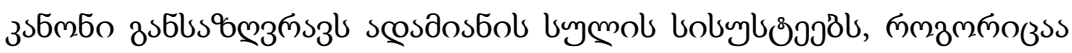

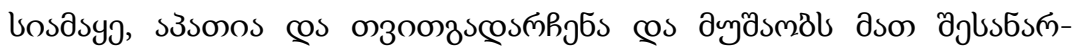

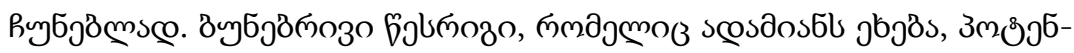

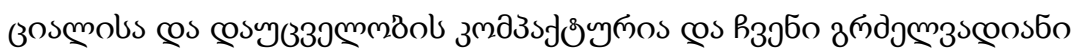

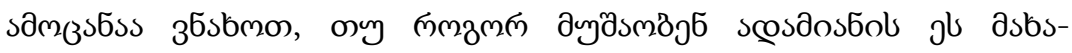

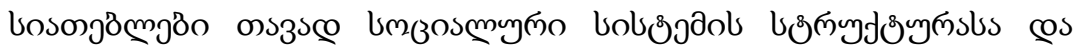

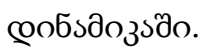




\title{
SOCIOLOGY OF LAW
}

\author{
Philip Selznick
}

Translated by Sophiko Metreveli*

\begin{abstract}
In this article Selznick developed the sociological imagination as a pointedly moral imagination, a vision of social science guided by moral philosophy, what Selznick himself called humanist science. This is a philosophy informed by the perpetual entwinement of human potential with human frailty. It makes the analyst sensitive to how ends are always interlinked with means, and how cherished ideals are inflected with an often-discouraging social reality. Only a morally subtle sociology can capture the moral ambivalence of human experience, the "recalcitrance of people, practices, and institutions, the precariousness of the finest ideals, the complexity and delicacy of attempts at institutional transformation, the ease with which fine motives are refracted in unexpected directions". Our means are sometimes tyrannical, our institutional goals, often displaced. And "not only are our tools recalcitrant; so too are we ourselves". Yet Selznick's scholarship consistently betrays a humble optimism: humble on the basis of hard, empirical realism about social institutions and their human environments, yet quietly optimistic because aware of the abiding potential, in humans and their institutional creations, for social progress.

Selznick think, at the level of analysis, by rejecting such determinism; and at the level of political action, with methods of taming power with power, by dividing it into factions, say, or decentralizing it. The moral point: the virtue of an organization's membership by itself is never enough for realizing normatively good outcomes; the hands even of good people need to be bound by rules.
\end{abstract}

* Ph.D. Candidate, Assistant, Manager for Planning and Development of Academic Research at Sulkhan-Saba Orbeliani University.

http://orcid.org/0000-0001-8480-2024 


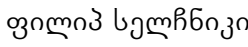

Key words: Sociology of Law, Social Organization, Crime, Law, Social Control, Social Organization. 